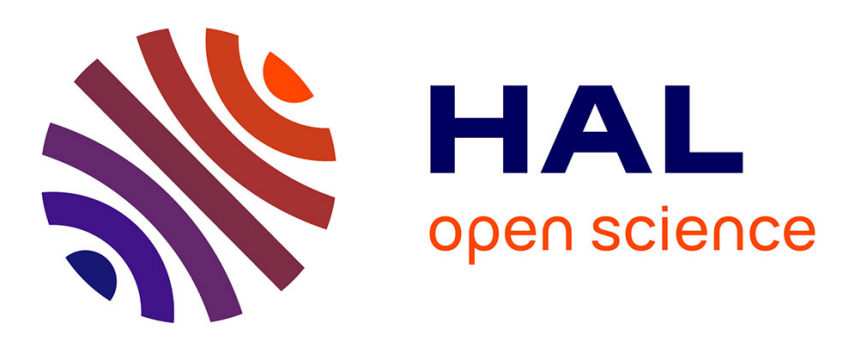

\title{
Fault Tolerant Multiphase Electrical Drives: The Impact of Design
}

Eric Semail, Xavier Kestelyn, Fabrice Locment

\section{To cite this version:}

Eric Semail, Xavier Kestelyn, Fabrice Locment. Fault Tolerant Multiphase Electrical Drives: The Impact of Design. European Physical Journal: Applied Physics, 2008, 43 (2), pp.159-162. 10.1051/epjap:2008057 . hal-00819009

\section{HAL Id: hal-00819009 \\ https://hal.science/hal-00819009}

Submitted on 29 Apr 2013

HAL is a multi-disciplinary open access archive for the deposit and dissemination of scientific research documents, whether they are published or not. The documents may come from teaching and research institutions in France or abroad, or from public or private research centers.
L'archive ouverte pluridisciplinaire HAL, est destinée au dépôt et à la diffusion de documents scientifiques de niveau recherche, publiés ou non, émanant des établissements d'enseignement et de recherche français ou étrangers, des laboratoires publics ou privés. 


\title{
Fault tolerant multiphase electrical drives: the impact of design
}

\author{
E. Semail, X. Kestelyn ${ }^{a}$, and F. Locment
}

L2EP ENSAM, 8 Bd Louis XIV, Lille 59046, France

Received: 28 June 2007 / Accepted: 22 February 2008

Published online (Inserted Later) - (c) EDP Sciences

\begin{abstract}
This paper deals with fault tolerant multiphase electrical drives. The quality of the torque of vector-controlled Permanent Magnet (PM) Synchronous Machine supplied by a multi-leg Voltage Source Inverter (VSI) is examined in normal operation and when one or two phases are open-circuited. It is then deduced that a seven-phase machine is a good compromise allowing high torque-to-volume density and easy control with smooth torque in fault operation. Experimental results confirm the predicted characteristics.
\end{abstract}

PACS. 84.50. + d Electric motors - 07.10.Pz Instruments for strain, force, and torque

\section{Introduction}

Three-phase Wye-connected machines supplied by VSI are the most common electrical drives. However, the tolerance to the loss of one or two phases, due to the failure of power devices of the VSI, is very low since there are only two independent currents. Various configurations to improve the reliability of the drive, keeping the same number of phases, have been studied $[1,2]$. A modification of the coupling allows recovering one freedom-degree: three currents are then independent. In any case, the original simplicity and low cost of the 3 -phase drive is lost.

Multiphase machines with more than three phases can be then considered [3,4]. Even if a higher number of connections is not well adapted for the reliability, these drives are interesting because of their fault-tolerant capability: they can continue to run even with one or two open-circuited phases. Moreover, the drawback of a higher price for these drives is not so obvious especially for low voltage/high current applications such as on-board systems $[5,6]$. For these systems, the current per phase can be so important that it is not possible to use only two power devices to achieve one leg of the VSI. Parallel/series transistor associations must be used $[7,8]$. In this case the overall number of transistors can be finally lower with a 5 -phase or a 7 -phase machine than with a 3 -phase machine. Moreover the impact of one transistor failure is less critical with multi-phase machines since it is possible to loose one phase: the overrating is consequently lower and a better thermal repartition of the transistors losses can be imagined.

If the loss of one or two phases is not as critical for fivephase [9] or seven-phase [4] machines as for three-phase machines, an important second time-harmonic torque ripples can appear because of the interactions between the

\footnotetext{
a e-mail: Xavier.Kestelyn@lille.ensam.fr
}

spatial harmonics of the electromotive forces (EMF) and magnetomotive forces (MMF) [10]. The reduction of these torque ripples is an important issue in fault operation.

Fault-tolerant controls of multiphase machines have been studied in the recent years for PM five-phase machines. One solution proposed in [11] for the problem of torque ripples is to impose a sinusoidal EMF for the machine. However, an interesting characteristic of the multiphase machines is lost in this case: low torque pulsations even with a trapezoidal EMF. This possibility is interesting since it allows at first to increase the torque density and secondly to reduce the constraints for the designer of the machine in terms of windings and permanent magnets shape.

Other solutions $[12,13]$ suggest changing the control structure when a fault occurs. A new transformation matrix is then used and the currents control is achieved in a new synchronous frame with Proportional Integral (PI) controllers. However, the control is consequently rather complex especially when a third harmonic exists.

In this paper, we show for $n$-phase PM synchronous machines that it is possible, if the total number of phase $n$ is enough high, to keep a trapezoidal EMF and also the same simple control structure as in normal operation. Only a few current references have to be modified. The approach is applied to a seven-phase machine in the cases of one or two open-circuited phases. The simplicity of the control relies on a design constraint of the 7-phase machine: its EMFs must contain only three harmonics: the first, the third and the seven ones.

In the first part of the paper, a characterization of multiphase machines torque is given. The origin of the torque ripples harmonics is exhibited and then a constraint on machine design, that is adapted for fault operation, is deduced. A control scheme in fault mode operation is presented. 
In the second part, experimental results are given for a vector-controlled 7 -phase machine that contains mostly the three imposed harmonics $[14,15]$. The mechanical torque is analyzed: in normal operation, when two phases are open-circuited with keeping the original control and when two phases are open-circuited using the improved control.

\section{Torque characterization of multiphase machines and deduced constraint}

It has been shown $[16,17]$ that a wye-connected $n$-phase machine with $n=2 F+1$ is equivalent to a set of $F$ twophase fictitious machines which are magnetically independent. Each fictitious machine $M_{g}$ is characterized by an EMF, a resistance, an inductance and a family of $n h \pm g$ odd harmonics $(1 \leq g \leq F)$. Torque $T$ of the $n$-phase machine is the sum of torques $T_{g}$ of the $\mathrm{F}$ fictitious machines.

$$
T=\sum_{g=1}^{g=F} T_{g} .
$$

Thanks to this multi-machine characterization, it is possible to show that the vector control of an $n$-phase machine can be deduced easily by implementing several times the $d_{q}$-frame vector control usually used for three-phase machines [17]. To ensure a pulsating torque equal to zero, it $n h \pm g$ is then sufficient that the EMF contains harmonics ranks lower than $n$. Indeed, according to the $n h \pm g$ odd harmonics associated with each fictitious machine, this condition ensures only one harmonic for each fictitious machine, i.e. each fictitous machine has a sinusoidal EMF. For a three-phase machine, it is found that the real machine can contain the first and third harmonics, i.e. the only two-phase $d_{q}$ fictitious machine has a sinusoidal EMF. For a seven-phase machine the first, third, five and seven harmonics are allowed.

Consequently it can be deduced that, if low torque ripples are required, the constraints on the harmonic EMF content are less important for the designer when the number $n$ of phases increases.

However, when one or two phases are open-circuited in a $n$-phase machine rotating at speed $\Omega=\omega / p$, with $p$ the number of pole pairs, large $2 \Omega$ torque pulsations can appear when the $d_{q}$ current references of the vector control are unchanged.

The calculus of new current references has been achieved for three-phase and five-phase machines controlled in the natural frame [11] and has led to quickly variable current references. The bandwidth of the current controllers must be large: hysteresis controllers are usually used [11] with the direct inconvenience of a large band spectrum (problems of EMC compliance).

When the third harmonic of EMF is chosen to be kept in order to get a high torque-to-volume density, the calculi are still more complex than with a sinusoidal EMF.

To solve this problem, $[12,13]$ propose to use PI controllers in $d_{q}$ frames. In these frames the time variations of the current references are slower and consequently PI type controllers can be used. Then, a usual Pulse Width Modulation with a fixed carrier frequency can be chosen. However, in $[12,13]$ the model in fault mode operation is not the same as in normal operation. For each fault mode operation a new structure of the model is chosen with a new transformation matrix and new reference frames. Consequently, the practical implementation of the control is heavy.

We have searched to keep advantages of both previously described approaches: a unique model for normal and fault mode operations and PI controllers in $d_{q}$ reference frames. However, this is only possible if design constraints are imposed to the multi-phase machine.

One solution is the following: the EMF of K two-phase fictitious machines must be equal to zero. Number $K$ is defined by the inequality: $2 K \geq G, G$ being the number of phases that can be lost. As an example, if one or two phases are lost, only one fictitious machine must have an EMF equal to zero.

This result is based on a few ideas.

At first, we consider that, even if in fault operation with open-circuited phases some actual currents are physically set to zero, the machine remains physically unchanged. The same machine model can be kept but some calculated current references must be modified to take into account these physical constraints.

In a second point, the loss of one or two phases corresponds to the loss of one or two freedom degrees. It is then impossible to impose the currents in all two-phase fictitious machines. Nevertheless, we consider that it is possible to choose the fictitious machine whose currents will not be controlled any more. If the EMFs of this machine are equal to zero, then the torque produced by this machine will be null even with non-controlled currents. Consequently, as supposing that the reference torques in the other fictitious machines are constant, the overall torque of the multiphase machine will be constant too.

It is possible now to examine the impact of the number of phases when this approach is applied. In the case of a three-phase machine there is no solution since there is only one two-phase fictitious machine. In the case of a fivephase machine, as there are only two two-phase fictitious machines, it remains only one fictitious machine whose EMFs can be not equal to zero: $M 1$ machine, associated with the first harmonic, is then chosen. Consequently, the third harmonic of the EMFs must be equal to zero. In fact, the EMFs of the real machine must be sinusoidal that is a severe constraint for the designer of the machine.

In the case of a seven-phase machine it remains two fictitious machines whose EMFs are not equal to zero. It is then interesting to choose $M 1$ and $M 3$ machines associated with the first and the third harmonics. We can thus deduce that $7 h \pm 2$ harmonic components of $M 2$ EMFs must be equal to zero. The first two corresponding harmonics are the fifth and the ninth ones. The amplitude of the ninth component is naturally weak. It is easy to suppress the fifth component of the EMF spectrum by acting either on the shape of the permanent magnets and/or on 


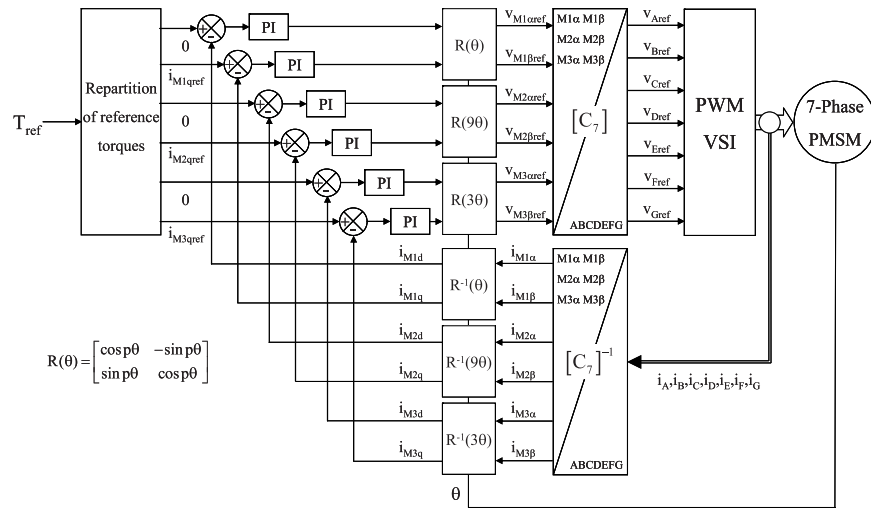

Fig. 1. Vector control in $d_{q}$ frames of a 7-phase machine.

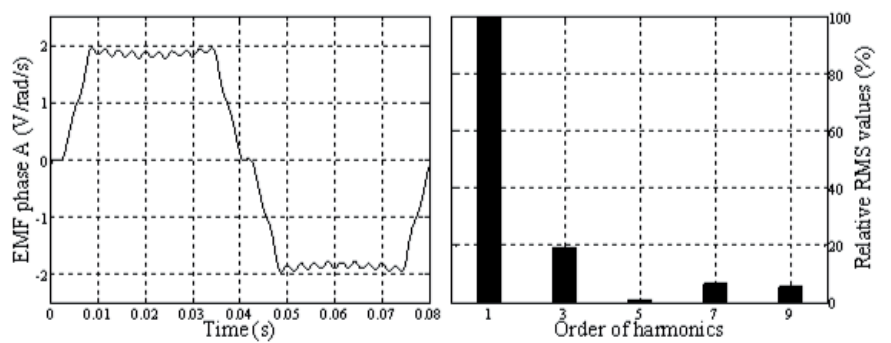

Fig. 2. Time and frequency characteristics of EMF.

the stator windings [21]. In most of the cases, due the large dimensions of the machine and the low number of poles pairs, the magnets shape can be easily adapted without any problems of industrialization. So it can be concluded that seven is the minimum number of phases which allows building a high torque-to-volume density fault tolerant machine without severe constraints on its design.

\section{Principle of control in fault mode peration}

We explicit in the following paragraph how it is possible, with a seven-phase machine whose EMFs of $M 2$ fictitious machine are null, to ensure low torque ripples when one or two phases are not supplied.

The control structure in fault operation with opencircuited phases is kept the same as in normal operation. The same machine model is kept but some calculated current references must be modified to take into account the physical constraints imposed by the open-circuited phases. The vector control of the machine is presented in Figure 1 [18]. We can recognize three times the same kind of control as for a three-phase machine. Of course, a Concordia matrix transformation $C_{7}$ extended to a sevenphase machine and three rotation matrixes whose angle is characteristic of each fictitious machine must be considered.

We take advantage of the fact that $M 2$ EMFs are equal to zero. Consequently, its current references do not have a direct impact on the torque. In normal operation, these references are set to zero in order to minimize the copper losses. In fault operation, current references will be calculated in order to impose constant torques in machines $M 1$
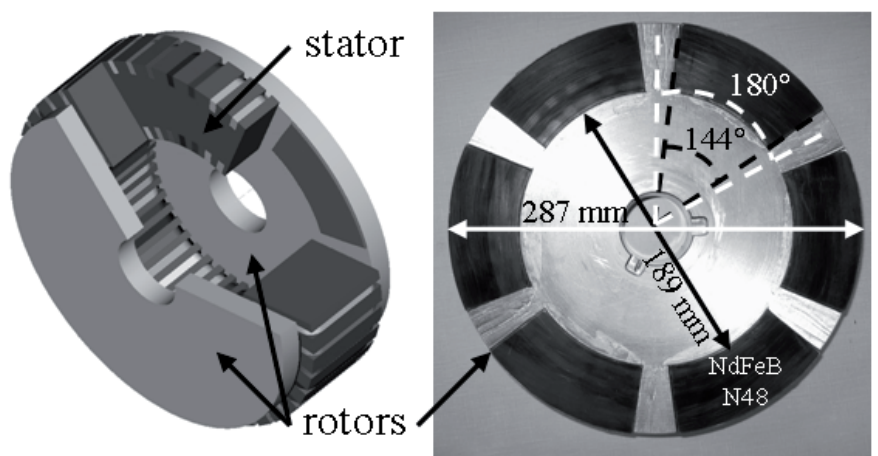

Fig. 3. Double rotor, toroidal winding machine (on the left) with detail of the rotor on the right.

and $M 3$ whereas one or two currents are equal to zero in one or two phases. By this way, the control scheme is the same as in normal operation, including the use of PI controllers. Only $M 2$ current references have to be changed in the "Repartition of reference torques" block (See Fig. 1).

As an example, when two phases shifted by $2 \pi / 7$ are open-circuited (phases $A$ and $B$ ), currents have to verify equation (2) which allows imposing the same currents in $M 1$ and $M 3$ as in normal mode:

$\left[C_{7}\right] \cdot\left[\begin{array}{c}0 \\ I_{M 1} \sin (\omega t) \\ -I_{M 1} \cos (\omega t) \\ i_{M 2 x} \\ i_{M 2 \beta} \\ I_{M 3} \sin (3 \omega t) \\ -I_{M 3} \cos (3 \omega t)\end{array}\right]=\left[\begin{array}{c}i_{A} \\ i_{B} \\ i_{C} \\ i_{D} \\ i_{E} \\ i_{F} \\ i_{G}\end{array}\right]=\left[\begin{array}{c}0 \\ 0 \\ i_{C} \\ i_{D} \\ i_{E} \\ i_{F} \\ -\left(i_{B}+i_{D}+i_{E}+i_{F}\right)\end{array}\right]$

The solution of equation (2) is:

$$
\left\{\begin{aligned}
i_{M 2 x}= & -I_{M 1} \sin (\omega t)-I_{M 3} \sin (3 \omega t) \\
i_{M 2 \beta}= & I_{M 1}(0.802 \cos (\omega t)-0.868(\omega t)) \\
& +I_{M 3}(0.445 \cos (3 \omega t)+0.696 \sin (3 \omega t))
\end{aligned}\right.
$$

\section{Experimental results with a fault tolerant axial-flux machine}

The previous theory has been applied to a seven-phase prototype whose harmonic spectrum is given in Figure 2. We have tried to get the lowest value for $M 2$ machine EMF whose main harmonics are the fifth and ninth ones.

In general, the right harmonic spectrum of the synchronous multi-phase machine can be obtained by acting either on the winding [19] or on the magnets shape. The studied prototype [16] is an axial flux PM machine with two external rotors and one internal stator with toroidal windings (see Fig. 3). In the case of axial flux machines, the physical constraints for making the windings are severe. There is an asymmetry relatively to the windings since it is more difficult to insert the end-windings at the inner radius than at the outside radius. It is difficult to achieve windings with more than one slot per pole and per 


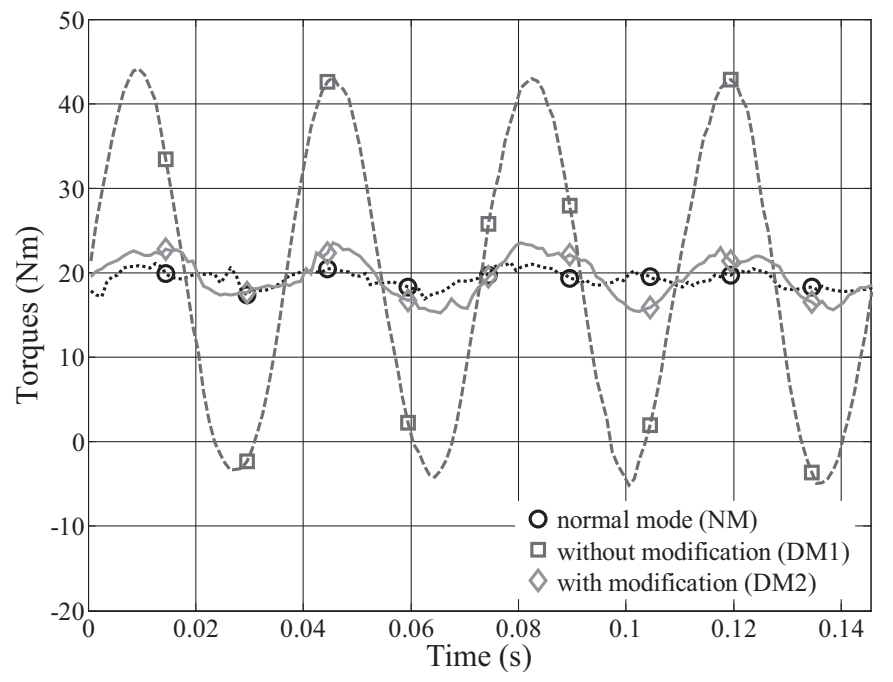

Fig. 4. Experimental mechanical torques.

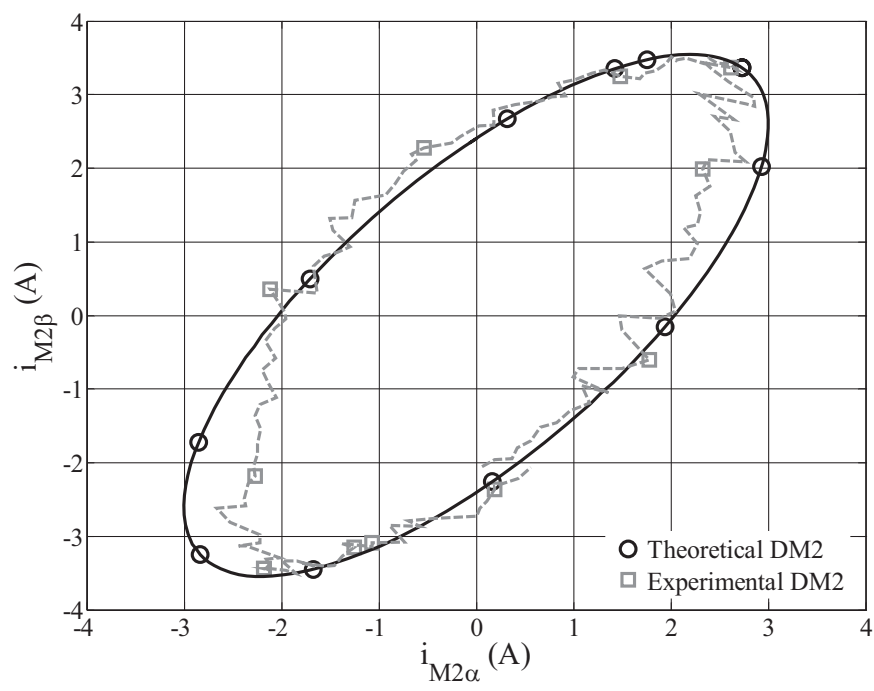

Fig. 5. Theoretical and experimental currents of the $M 2$ machine.

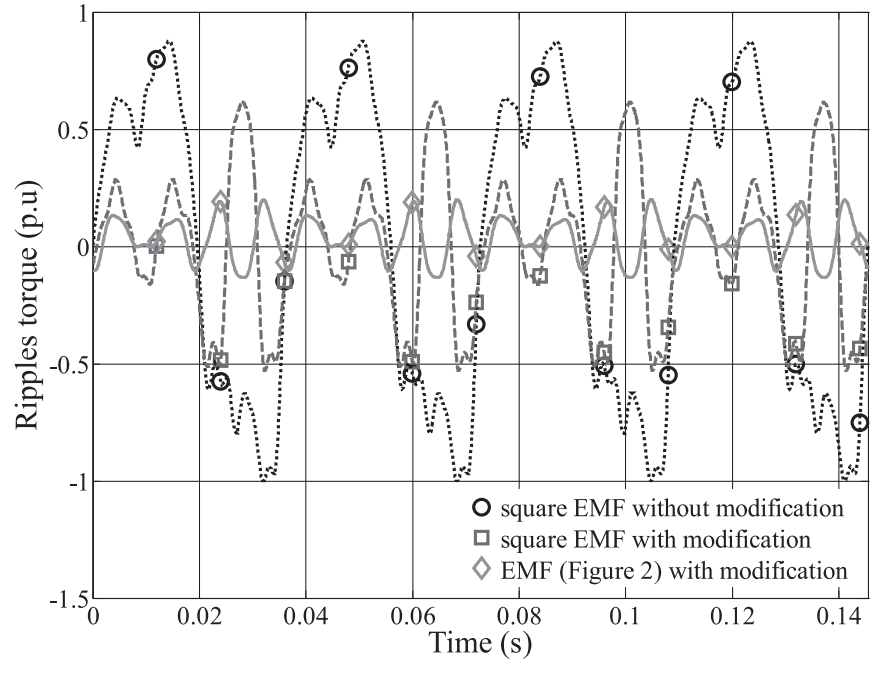

Fig. 6. Effect of a fifth harmonic on the electromagnetic torque.

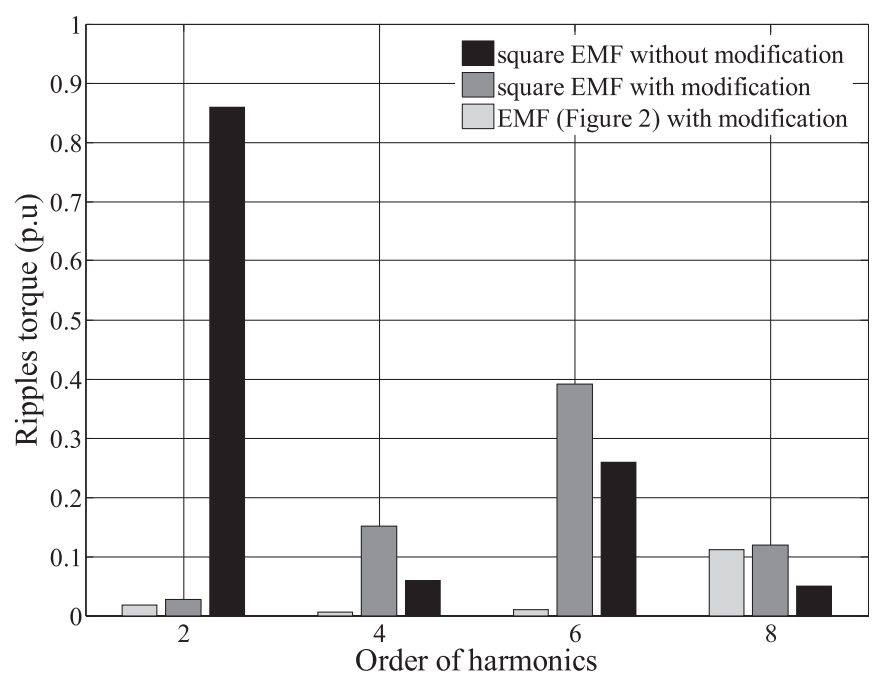

Fig. 7. FFT of electromagnetic torques.

sating torque appears for case DM1: about a peak-to-peak variation of $70 \%$ of the rated torque. It results from the interaction between the first harmonic of currents and the third harmonic of EMF. For DM2 case, the references obtained by equation (3) are imposed to the PI controllers of M2 machine and lead to ripples torque which amplitude is of the same order (less than $6 \%$ of the rated torque) as in normal mode (less than $3 \%$ of the rated torque). In Figure 5, reference and experimental current vectors of M2 machine in $\alpha \beta$ plane are given. In accordance with equation (3), the reference vector follows an ellipse locus. If globally, the experimental current vector tracks the reference, an error exists. Consequently, currents in $M 1$ and M3 machines can not be perfectly constant and a little torque ripple appears. However the reduction is significant. 
In order to point out the impact of the fifth harmonic of EMF, a simulation has been achieved with a seven-phase machine for which we have only changed the waveform of the EMF: a square waveform has been chosen with consequently a ratio of $20 \%$ between the fifth and the first harmonics.

We can observe in Figure 6 by comparison of the curves (circle and square pictograms) that the modification of the current references has a good impact on the torque ripples, even if the machine has a square EMF. It is due to the fact that this strategy imposes a constant torque in machines $M 1$ and $M 3$. Nevertheless, the effect of the special machine design is obvious by comparison of the curves (square and diamond pictograms): a reduction of the torque ripples can be noticed.

Figure 7 shows the effect of the EMF harmonic content versus the electromagnetic torque ripples. Keeping the initial control (without modification), the interaction between the EMFs and currents leads to high second, fourth and sixth torque harmonics. With the improved control and a square EMF, the second harmonic disappears and it remains mainly a fourth and a sixth harmonic. This is mainly due to the fifth harmonic of EMF. Finally, with the EMF of the presented machine, it remains only an eight harmonic due to the interaction of the first harmonic of current with the

\section{Conclusion}

In this paper, we have presented, thanks to an analysis of the torque characteristics of the multiphase machines, the harmonic constraints that allow verifying several objectives: a third harmonic EMF component for high torque-to-volume density, a constant torque when one or two phases are open-circuited, an unchanged structure of the vector control. We have then considered a seven-phase machine that verified the previous objectives. Experimental results confirm that a simple modification of the current references allows effectively working with two open-circuited phases and very low torque ripples. More generally, we have shown how a little modification on the design of the machine makes easier the control in fault mode operation. Of course, for a seven-phase machine, the cancellation of the fifth harmonic of EMF leads to a slight reduction of the torque to volume ratio (less than $5 \%$ in our case in comparison with a theoretical square -wave EMF machine). Finally, the best moment to switch between current references in normal and fault mode has to be studied in order to reduce the induced transient phenomena.

\section{References}

1. B.A. Welchko, A. Lipo, T.M. Jahns, S.E. Schulz, IEEE Trans. on Power Electronics 19, 1108 (2004)

2. B. Keith, I. Ramesohl, S. Reck, H. Schwab, G. Sturtzer, Proc. of EPE'03, CD-ROM, Toulouse (France), September 2003

3. B.C. Mecrow, A.G. Jack, J.A. Haylock, J. Coles, IEE ProcElectr. Power Appl. 143, 437 (1996)

4. J. Figueroa, J. Cros, P. Viarouge, CD-ROM, Toulouse (France), September 2003

5. B.C. Mecrow, A.G. Jack, D.J. Atkinson, S. Green, G.J. Atkinson, Design and Testing of a 4 Phase Fault Tolerant Permanent Magnet Machine for an Engine Fuel Pump, IEEE-IEMDC'03, CD-ROM, Madison (USA), June 2003

6. A. Krautstrunk, P. Mutschler, IFAC-Conference on Mechatronic Systems 1, 45 (2000)

7. A. Lindemann, Power Electronic Supply of Automotive Starter Generator, Power Electronics Europe, issue 4, 2001

8. J. Liu, J. Hu, L. Xu, Proc. of IEEE-IAS'04 4, 2754 (2004)

9. T. Gopalarathnam, H.A. Toliyat, J.C. Moreira, Proc. of IEEE-IAS'00 3, 1683 (2000)

10. H.M. Ryu, J.H. kim, S.K. sul, IEEE Trans. on Industry Applic.42, 1062 (2006)

11. L. Parsa, H.A. Toliyat, Proc. of IEEE-IAS'04 2, 1048 (2004)

12. H.M. Ryu, J.H. Kim, S.K. Sul, IEEE Trans. on Industry Applic. 42, 1062 (2006)

13. E. Robert-Dehault, M.F. Benkhoris, E. Semail, Study of a 5-phases synchronous machine fed by PWM inverters under fault conditions Proc. of ICEM2002, CD-ROM, Brugge (Belgium), August 2002

14. F. Locment, E. Semail, F. Piriou, IEEE Trans. on Magnetics, 42, 1427 (2006)

15. F. Locment, E. Semail, F. Piriou, Soft Magnetic Composite Axial Flux Seven-Phase Machine, Proc. of ICEM'06, CDROM, Chania, (Greece), Sept. 2006

16. E. Semail, A. Bouscayrol, J.P. Hautier, Eur. Phys. J. A. P 22, 207 (2003)

17. E. Semail, X. Kestelyn, A. Bouscayrol, Proc. of IEEEIAS'04 1, 71 (2004)

18. F. Locment, E. Semail, X. Kestelyn, A. Bouscayrol, Control of a seven-phase axial flux machine designed for fault operation, Proc. of IECON'06, Paris (France), November 2006

19. F. Scuiller, J.F. Charpentier, E. Semail, S. Clénet, A global design strategy for multiphase machine applied to the design of a 7-phase fractional slot concentrated winding PM machine, Proc. of ICEM'06, CD-ROM, Chania, (Greece), September 2006

20. F. Scuiller, E. Semail, J.F. Charpentier, S. Clénet, IASME Trans. 1, 365 (2004)

21. J.R. Hendershot Jr TJE Miller Magna Physics 100 Publication. Oxford Science Publication. 